\title{
A FALÊNCIA DO SISTEMA PENITENCIÁRIO BRASILEIRO: UMA REFLEXÃO SOBRE A RECUPERAÇÃO POR INTERMÉDIO DA PRIVATIZAÇÃO
}

\section{Marina Calanca Servo* Ana Cristina Lemos Roque}

\begin{abstract}
RESUMO: O presente ensaio tem como objetivo uma reflexão a respeito da falência do sistema penitenciário brasileiro que além de não atingir as finalidades previstas ao efetivar a sentença condenatória através da pena privativa de liberdade, consiste atualmente em afronta gritante aos direitos e garantias fundamentais. Em que pese inúmeras críticas a privatização, a mesma consiste em possível solução, conforme será analisado. A pesquisa foi desenvolvida através de análise bibliográfica e de dados colhidos e apresentados pelo Conselho Nacional de Justiça, o método histórico-evolutivo foi utilizado em conjunto com o dialético mediante diálogo entre as transformações da pena e a realidade.
\end{abstract}

PALAVRAS-CHAVE: Privatização; Penitenciárias; Ressocialização. Finalidades da pena. Direito Penal.

\section{THE BANKRUPTCY OF THE BRAZILIAN PENITENTIARY SYSTEM: A REFLECTION ON THE RECOVERY THROUGH PRIVATIZATION}

\begin{abstract}
The purpose of this essay is to reflect on the failure of the Brazilian penitentiary system, which, in addition to failing to achieve the intended purposes of carrying out the criminal sentence, currently consists of a striking affront to fundamental rights and guarantees. Despite numerous criticisms of privatization, it consists of a possible solution, as will be analyzed. The research was developed through bibliographic analysis, data collected and presented by the National Council of Justice, the historical-evolutionary method was used in conjunction with the dialectic through dialogue between the transformations of the penalty and the reality.
\end{abstract}

KEY WORDS: Privatization, Penitentiaries, Resocialization, Purpose of the penalty. Criminal Law.

\section{INTRODUÇÃO}

De acordo com o levantamento nacional de informações penitenciárias (INFOPEN), atualizada em 09 de abril de 2020, no período de julho a dezembro de 2019, a população prisional

\footnotetext{
* Mestranda na Faculdade de Direito de Ribeirão Preto (FDRP/USP). Especialista em Direito Penal e Processual Penal, graduada em Direito pela Universidade Paulista. Advogada militante. Professora em Instituição de Ensino Superior, em curso preparatório para segunda fase do Exame de Ordem e concursos públicos. Email para contato: marinacservo@gmail.com.

** Doutoranda em Direitos Humanos pela Faculdade de Direito da Universidade de São Paulo - FDUSP, Mestre em Direito na área de concentração "Teoria do Direito e do Estado" bolsista CAPES/PROSUP. Advogada e Professora na Comarca de São José do Rio Preto-SP.
} 
correspondia a 755.274 (setecentos e cinquenta e cinco mil duzentos e setenta e quatro) detentos entre unidades prisionais e outras carceragens ${ }^{\dagger}$, havendo déficit de 312.925 (trezentos e doze mil novecentas e vinte e cinco) vagas.

Tais números revelam que o Brasil é o terceiro país que mais encarcera no mundo - atrás de China (segundo lugar) e Estados Unidos, sendo que entre 1990 e 2019, a taxa de aprisionamento aumentou em $359 \%$ (trezentos e cinquenta e nove por cento), conforme consta do sétimo painel interativo (referente aos dados divulgados em dezembro de 2019).

O crescente número fomenta a discussão sobre a (in)eficácia do sistema penitenciário, diante da análise das finalidades da pena previstas no ordenamento jurídico brasileiro, inclusive considerando que parte dos indivíduos detidos são egressos do próprio sistema.

A forma punitiva implementada pelo Brasil, sobretudo a pena privativa de liberdade vem fomentando debates sobre as garantias constitucionais dos condenados principalmente quando se depara com um crescente aumento da criminalidade e não resolução do problema da violência, por conta das atuais situações desumanas encontradas nos presídios nacionais.

Certo é que a pena privativa de liberdade nestes moldes faliu. É hora de rever a dogmática punitiva nacional e propor pelo menos uma forma de melhoria do sistema. Assim, a reflexão buscada neste trabalho tem como cenário a aplicação da pena privativa de liberdade, especialmente em regime fechado, partindo-se do preceito de que pena está sendo aplicada, através da sentença, como consequência da lei, sem abordar eventual desproporcionalidade que pode existir entre a conduta praticada e o quantum de pena imputado em abstrato ou em concreto.

Mas para adjetivar como eficaz ou ineficaz a execução realizada pelo Estado é imprescindível comparar os números acima em detrimento das finalidades da pena no contexto histórico e atual, o que motivou a abordagem das transformações da pena, mediante análise bibliográfica e histórico-evolutiva sobre o tema. Posteriormente é realizada a explanação sobre os sistemas penitenciários, para compreender a afirmação que fundamenta a falência apontada no título. Por fim, a privatização é apresentada como forma de recuperação do sistema atual, o método dialético foi adotado como forma de diálogo entre as transformações da pena e a as violações legais pela realidade.

\section{DAS TRANSFORMAÇÕES DA PENA}

\footnotetext{
${ }^{\dagger}$ Tais informações podem ser obtidas através de consulta do Infopen, que compila informações estatísticas do sistema penitenciário brasileiro, por meio de um formulário de coleta preenchido pelos gestores de todos os estabelecimentos prisionais do país com a finalidade de diagnóstico da realidade prisional brasileira.
} 
A primeira sanção relatada, para os criacionistas, consiste na expulsão de Adão e Eva do jardim do Éden, apresentada na Bíblia Sagrada, como forma de punição diante da desobediência e transgressão a regra anteriormente estipulada.

$\mathrm{Na}$ antiguidade, aproximadamente do século VIII a.C. ao século V d.C, a restrição da liberdade era forma de contenção do réu até o seu julgamento, de acordo com Bittencourt (2011, p. 31), utilizavam-se horrendos calabouços, aposentos frequentemente em ruínas ou insalubres de castelos, torres, conventos abandonados, palácios e outros edifícios.

Na Idade Média, do século V d.C ao século XV d.C., é mencionada a prisão eclesiástica, que se destinava aos clérigos rebeldes e respondia às ideias de caridade, redenção e fraternidade da Igreja, dando ao internamento um sentido de penitência e meditação. Recolhiam-se os infratores em uma ala dos mosteiros para que, por meio de penitência e da oração, se arrependessem do mal causado e obtivessem a correção ou emenda.

Assim, a finalidade da reclusão era que o indivíduo encontrasse o arrependimento e através deste recebesse a purificação divina pelo pecado.

Já na Idade Moderna, do século XV d.C ao século XVIII d.C., na segunda metade do século XVI iniciou-se um movimento de grande transcendência no desenvolvimento das penas privativas de liberdade, na criação e construção de prisões organizadas para a correção dos apenados (BITTENCOURT, 2011, p. 38).

Deu-se início as "instituições de correção" que tinham como intuito a internação dos transgressores para que fossem reformados, por meio do trabalho e da disciplina, tirando-os da ociosidade. Acredita-se que essas instituições de correção tiveram um grande êxito, porque após elas, começaram a surgir na Inglaterra as chamadas "houses of corrections" (casas de correção) e posteriormente as "work houses" (casas de trabalho), com a finalidade em corrigir o indivíduo através do trabalho realizado.

A partir do século XVIII d.C., com influência do iluminismo, responsável por revolucionar o Direito Penal através de grandes filósofos e sociólogos, como Cesare Bonesana, marquês de Beccaria, passou-se a discussão sobre humanização das penas com a transcendência da finalidade punitiva ou unicamente como retribuição do mal causado a vítima.

A pena privativa de liberdade, como salientava Beccaria (2003), foi sim um avanço para humanização da justiça, que veio substituir penas capitais e corporais, no entanto, passados quase 230 anos de sua implantação, no primeiro Código Penal Francês (1791), a criminalidade não 
diminuiu, e os egressos dos sistemas penitenciários continuam sendo marginalizados pela sociedade, pois não há humanização nem racionalização, apenas são apartados temporariamente do convívio social, integrando um Estado paralelo onde lhe é retirado a personalidade, perdendo sua identidade e consequentemente, retornando ao local de onde nunca saíram, num ciclo infinito.

Assim, diversas teorias emergiram trazendo distintas no caráter adotado para a pena entre as finalidades de prevenção de crime, punição e/ou de ressocialização.

\section{DAS FINALIDADES DA PENA E SISTEMAS PENITENCIÁRIOS}

O Direito Penal possui um caráter fragmentário, cujo objeto de trabalho é aplicação da pena, com o fim de que sejam coibidos ou amenizados os atos lesivos ao indivíduo e à sociedade. Assim, a pena assume um caráter de reação do Estado à violência do cidadão contra seu igual ou contra a sociedade. Não é função do Direito Penal coibir todo e qualquer ataque a bens jurídicos, “mas somente as modalidades de ataque mais perigosas aos mesmos” (MIR PUG, 2007, p. 94).

É importante ressaltar que o Direito Penal, deve ser utilizado com parcimônia, com cautela, pois constitui a brutalidade reativa do Estado frente ao cidadão. Não se justifica o uso do Direito Penal em casos que poderiam ser resolvidos por outros ramos do Direito.

O Estado Democrático de Direito é a base do nosso sistema constitucional, e neste, as ações penais são utilizadas em último caso, deve-se, antes, valer-se de outros ramos do Direito, como o Direito Civil - por meio de reparações de dano e devolução dos produtos do enriquecimento ilícito - ou do Direito Administrativo - podendo utilizar multas, sanções disciplinares, revogação de concessões.

Por mais que a população deseje a aplicação do Direito Penal, somente será lícito seu uso quando outros ramos do direito forem insuficientes para a solução de conflitos:

o princípio da ultima ratio (também chamado subsidiariedade) indica-nos que a pena é o último recurso de que dispõe o Estado para resolver os conflitos sociais. Em outras palavras, que somente pode recorrer ao Direito Penal quando fracassado as outras instâncias de controle social que tenham capacidade para resolver o conflito é cada vez mais frequente a denúncia de utilização do direito penal, não como ultima ratio senão como sola ou prima ratio para solucionar os conflitos sociais. (Ferré Olivé; Roxin, 2011, p. 94-95).

É senso comum que o Direito Penal pode resolver os problemas da criminalidade mediante penas mais duras e de uma maior intervenção estatal na vida dos indivíduos. Cada vez 
mais, a mídia incita a resolução de conflitos por meio da penalização, gerando uma falsa ideia de que o Direito Penal seria a solução imediata para todos os conflitos, afogando o sistema carcerário e gerando riscos para detentos, agentes e sobretudo para a sociedade.

Para isso, é cabível dizer que o legislador, ao escolher quais condutas devem ser criminalizadas, deve sopesar a real existência de merecimento da pena, analisando se o bem jurídico albergado possui dignidade penal e se a conduta do agressor ofende de forma considerável, a ponto de haver necessidade do amparo penal e o encarceramento, tendo em vista que a intervenção penal é uma violência à liberdade do indivíduo e deve ser restrita a situações de extrema necessidade, ou seja, apenas onde os demais ramos do direito não conseguiram atuar.

[...] o homem se cansa de atormentar a seu semelhante indefeso. $\mathrm{O}$ crime mais horrível resulta, ao final de um ou mais anos, em uma página de crônica de um tempo quase esquecido. $\mathrm{O}$ desgosto contra seu autor é uma impressão que, como todas as demais, debilita-se pelo tempo e com a familiaridade vivida com o réu. Uma vez velho e abatido, já não suscita nossa invencível antipatia como nos primeiros momentos logo após o delito. Um tratamento excessivamente rígido chega a parecer uma inútil crueldade. Se ele sofre, se pede, por piedade, não ser obrigado a enlouquecer entre as quatro paredes de sua cela, seus gemidos acabam por encontrar acolhida (Garófalo 1896, p. 97).

Nesse contexto, o Código Penal, com a alteração em 1984, passou a estipular que a pena deve ser fixada considerando a dupla função, de modo a ser suficiente para reprovar e prevenir novos crimes

Já a Lei de Execução Penal, também de 1984, trouxe no art. $1^{\circ}$, o objeto e aplicação da lei mencionada, que consiste em efetivar as disposições da sentença condenatória (ou absolutória imprópria), bem como condições para reintegração social do condenado ou do internado, no caso de medida de segurança, com a concessão de assistência ao preso, visando prevenir o crime e orientar o retorno a sociedade ${ }^{\S}$. Assim, o ordenamento jurídico brasileiro adotou como finalidades da sanção penal, a prevenção, retribuição e ainda a ressocialização, o que consiste na denominada teoria "mista", junção das correntes absoluta e relativa.

Para a corrente "absolutista", a pena tem caráter punitivo, sendo utilizada como retribuição do mal causado, ou seja, o Estado impõe a pena com o intuito de punir o indivíduo

\footnotetext{
"De acordo com o art. 59, do Código Penal, "O juiz, atendendo à culpabilidade, aos antecedentes, à conduta social, à personalidade do agente, aos motivos, às circunstâncias e consequências do crime, bem como ao comportamento da vítima, estabelecerá, conforme seja necessário e suficiente para reprovação e prevenção do crime".

${ }^{\S} \mathrm{O}$ art. $1^{\circ}$, da Lei n. $7.210 / 1984$, dispõe que "a execução penal tem por objetivo efetivar as disposições de sentença ou decisão criminal e proporcionar condições para a harmônica integração social do condenado e do internado".
} 
infrator. Haroldo Caetano e Silva (2002, p.35), aponta que nessa teoria, a pena não tem finalidade, trata-se de um fim em si mesma.

Já para a corrente utilitarista, a pena funciona como instrumento de prevenção de novos delitos, com a finalidade inibitória, sendo que essa prevenção se divide em "geral" e "especial". Para a primeira, o principal escopo e efeito da pena é a inibição que esta causa sobre a generalidade dos cidadãos, intimidando-os. Para a segunda, a pena visa a intimidação do agente, de modo que o Estado pune para que o criminoso não volte a delinquir.

Nota-se que o Direito Penal brasileiro, ao buscar a retribuição, bem como a prevenção, diante da aplicação da pena, demonstrou a adoção da corrente eclética, também denominada de mista ou unificadora. No que condiz aos sistemas penitenciários, existem três sistemas básicos: Sistema Pensilvânico ou Filadélfico, Sistema Auburniano e Sistema Progressivo.

Damásio de Jesus (2004, p. 249) explica que no Sistema Pensilvânico "utiliza-se o isolamento celular absoluto, com passeio isolado do sentenciado em um pátio circular, sem trabalho ou visitas, incentivando-se a leitura da bíblia" como forma de arrependimento do delito e perdão da sociedade. Já o sistema Auburiano também determina o isolamento do preso, mas o encaminhamento a cela ocorria apenas a noite, pois de dia "era reunidos durante algumas horas, para poder dedicar-se a um trabalho produtivo (BITTENCOURT, 2011, p. 95).

Já o sistema Progressivo, tem como essência que seja retomado o convívio em sociedade, com a progressão para regime menos gravoso, estimulando um bom comportamento por parte do detento, conforme aponta Bitencourt (2011, p. 97-98) ${ }^{* *}$. Nota-se que o Brasil adotou o Sistema Progressivo, previsto na Lei de Execução Penal ${ }^{\dagger \dagger}$, que prevê a progressão de regime para um menos rigoroso quando preenchidos os requisitos, sendo considerada inconstitucional, pelo Supremo Tribunal Federal, a vedação da progressão de regime, inclusive para crimes hediondos.

Assim, tendo sido adotado o sistema mais coerente com as finalidades da pena previstas Código Penal e harmonioso com princípio fundamental da dignidade da pessoa humana, previsto

\footnotetext{
** De acordo com o autor, o sistema progressivo é caracterizado por “distribuir o tempo de duração da condenação em períodos, ampliando-se em cada um dos privilégios que o recluso pode desfrutar de acordo com sua boa conduta e o aproveitamento demonstrado do tratamento reformador. Outro aspecto importante é o fato de possibilitar ao recluso reincorporar-se à sociedade antes do término da condenação. A meta do sistema tem dupla vertente: de um lado pretende constituir um estímulo à boa conduta e a adesão do recluso ao regime aplicado, e, de outro, pretende que esse regime, em razão da boa disposição anímica do interno, consiga paulatinamente sua reforma moral e a preparação para a futura vida em sociedade" (BITTENCOURT, 2011, p. 97-98).

${ }^{\dagger}$ De acordo com o art. 112, da Lei n. 7.210/1984, a pena privativa de liberdade será executada em forma progressiva com a transferência para regime menos rigoroso, a ser determinado pelo juiz, quando o preso tiver cumprido ao menos um sexto da pena no regime anterior e ostentar bom comportamento carcerário, comprovado pelo diretor do estabelecimento, respeitadas as normas que vedam a progressão.
} 
na Carta Magna, teoricamente se mostraria injustificável o questionamento a respeito da eficácia do sistema. Entretanto, a realidade é diversa, diante da crescente criminalidade já mencionada.

\section{A FALÊNCIA DO SISTEMA}

Os problemas carcerários somente tomam evidência quando já estão acontecendo motins, que aliás, sendo uma das formas de protestos mais eficazes, onde os detentos gritam à sociedade e ao poder público que estão sendo violados. Assim, as rebeliões:

É o acontecimento que causa maior impacto e o que permite à sociedade tomar consciência, infelizmente por pouco tempo, das condições desumanas em que a vida carcerária se desenvolve [...] o motim rompe o muro de silêncio que a sociedade levanta ao redor do cárcere. A imensa maioria dos protestos reivindicatórios massivos produzidos na prisão tem sua origem nas deficiências efetivas do regime penitenciário. As deficiências são tão graves, que qualquer pessoa que conheça certos detalhes da vida carcerária fica profundamente comovida. (BITTENCOURT apud CARVALHO, 2003, p.234).

Esta postura vingativa da sociedade, revela o baixo grau de evolução civilizatória de um povo, que tem dificuldade em reconhecer os direitos humanos à todos, indistintamente. Nesse sentido afirma Bobbio (1992, p. 45):

A proclamação e o reconhecimento dos direitos do homem, para o processo penal, não são suficientes, na medida em que sua efetivação depende de questões culturais e evolução social. O sistema jurídico pode até estabelecer regras de proteção a determinados direitos, mas a sua eficácia está vinculada à evolução civilizatória.

A prisão nos moldes tradicionais, não consegue, por carência estrutural e econômica, nem tem o verdadeiro intuito de reabilitar o condenado. Tal crise penitenciaria vem se mostrando a nível mundial, alerta Carvalho Filho (2002, p. 29):

Países pobres e países ricos enfrentam dificuldades. Cárceres superlotados na Europa, na América, na Ásia, no Oriente Médio. Prisões antiquadas na Inglaterra. Violência entre presos na Finlândia. Violência sexual nos EUA. Adolescentes e adultos misturados na Nicarágua. Presos sem acusação no Egito. Maioria de detentos não sentenciados em Honduras. Massacres na Venezuela. Isolamento absoluto na Turquia. Greve de fome na Romênia. Prisioneiros que mutilaram o próprio corpo para protestar contra condições de vida no Cazaquistão. Doença e desnutrição no Marrocos. Mais de 96 mil tuberculosos na Rússia. Presos sem 
espaço pra dormir em Moçambique. Tortura e número de presos desconhecidos na China.

Na dinâmica do século XIX, acreditou-se que a pena privativa de liberdade seria o grande trunfo para a reforma do delinquente. Este pensamento otimista já não vigora no período atual onde as esperanças depositadas na prisão tradicional já não satisfazem as expectativas.

As principais premissas deste pessimismo advêm dentre tantas hipóteses da utilização de um meio artificial antinatural com propósitos de reabilitar o indivíduo que vive numa comunidade livre. Indaga-se, se esses indivíduos antissociais um dia se querem, foram sociais.

Antônio Garcia - Pablos Y Molina (1988, p.41), assevera que "a pena não ressocializa, mas estigmatiza, não limpa, mas macula, como tantas vezes se tem lembrado aos expiacionistas"; que é mais difícil socializar a uma pessoa que sofreu uma pena do que outra que não teve essa amarga experiência; que a sociedade não pergunta porque uma pessoa esteve em um estabelecimento penitenciário, mas, se lá esteve ou não.

Para Giacóia, Hammerschmidt e Fuentes (2011, p. 144) “o estigma da prisão acompanha o egresso, dificultando ou impedindo seu regresso à vida social" e continua:

Estar detido, não é só a perda do direito à liberdade, é muito mais [...]Os efeitos secundários ou colaterais da restrição da liberdade são muitas vezes mais graves que a própria pena, especialmente quando se refletem ou se transferem a terceiros. Assim, a estigmatização e o rótulo dos ex-presidiários não se vinculam somente a seus familiares, mas também a seus vizinhos e companheiros de trabalho, a todo o entorno do sujeito, trazendo graves consequências que nunca poderão ser reparadas.

A manifesta deficiência das condições penitenciárias existentes no mundo advém grande parte, do descaso da sociedade e sobretudo dos governantes estando apenas o caminho das reformas mais ou menos radicais que permitam reverter a pena privativa de liberdade em meio efetivamente reabilitador.

A prisão constitui uma fonte criminógena além de não trazer nenhum benefício ao apenado, ainda pode trazer todo tipo de vícios e degradações. A deficiência de alojamentos e alimentação facilita o desenvolvimento da tuberculose, deteriora a saúde dos reclusos pelas más condições de higiene por conta da falta de circulação de ar e constante respiro dos odores nauseabundos. (BITENCOURT, 2011, p. 179 -180).

Os órgãos fiscalizadores de aplicação da pena, ou seja, Judiciário, Ministério Público e Defensoria Pública, acabam por não realizarem tais deveres, por conta da carga elevada de 
trabalho e mesmo pela carência de investimento nos estabelecimentos penais, ficando assim de mãos atadas, o que corrobora na linha de pensamento aduz Kloch e Motta (2008, p. 62), “[...] em que se evidencia que o Poder Público está perdendo o controle na aplicação da pena, como instrumento de recuperação do apenado". Assim, não fiscalizam a administração do Poder Executivo nem a observância da Lei das Execuções Penais.

Pesquisa realizada pelo Instituto de Pesquisa Econômica Aplicada (Ipea) a pedido do Conselho Nacional de Justiça $(\mathrm{CNJ})$, apontou que um em cada quatro ex-condenados se torna reincidente, diante da prática de novo crime, no período de cinco anos, uma taxa de $24,4 \%$ (IPEA. 2015, p. 23).

No que condiz as causas que elevam o número da criminalidade e da reincidência, diversas poderiam ser mencionadas, mas abordaremos neste trabalho àquelas vinculadas a ausência de ressocialização dos indivíduos e a incapacidade do sistema em reinseri-lo na sociedade.

Mais do que isso, tais números demonstram que o Estado também não é capaz de efetivar a finalidade preventiva da pena, restando somente a reflexão se a retribuição é realizada de forma adequada. Arriscamos apontar que não. A punição, através do cárcere, tem sido uma afronta a princípios fundamentais, além de preceitos previstos no Pacto de Direitos Humanos e da Lei de Execuções Penais.

A superlotação das penitenciárias, condições das celas - escuras, sem ventilação, ambientes insalubres e com segurança precária, geram a proliferação de doenças, tornando os presídios incapazes de efetivar qualquer das finalidades da pena, sendo, inclusive, uma punição ainda mais gravosa do que a prevista no Código Penal.

A averiguação de tais condições foi utilizada como fundamento, por parte do Supremo Tribunal Federal para restabelecer a condenação Estatal ao pagamento indenizatório diante dos danos extrapatrimoniais sofridos por um detento que suportou condições degradantes, durante o cumprimento da pena no RE 580252/MS, que teve como relator o Ministro Teori Zavascki e relator para Acórdão, o Ministro Gilmar Mendes, no julgamento na data de 16/02/2017, em Tribunal Pleno.

A superlotação dos presídios é um dos maiores e mais visíveis problemas do sistema penitenciário, sendo que, de acordo com o último levantamento nacional de informações penitenciárias (INFOPEN), atualizada em 09 de abril de 2020, referente ao período de julho a 
dezembro de 2019, há um déficit de vagas de 312.925 (trezentos e doze mil novecentas e vinte e cinco) nas penitenciárias do país.

Geopresídio consistem em um projeto do Conselho Nacional de Justiça conceituado como uma "radiografia do sistema prisional", que apresentam informações de todos os Estado da federação, tendo como fonte o relatório mensal do Cadastro Nacional de Inspeções nos Estabelecimentos Penais (CNIEP), e são divulgados através do site oficial do Conselho Nacional de Justiça.

De acordo com a plataforma, o "déficit" de vagas fica entre $15,42 \%$ no estado da Bahia (sendo o mais baixo) e o "déficit" de 184,10\% no estado de Pernambuco (o mais alto da federação), havendo outros dois estados que apresentam "déficit" acima de 100\%, sendo o estado de Roraima (143,13\%) e Distrito Federal $(115,42 \%)$.

Evidente que quanto maior o número de encarcerados além da quantidade de vagas suportadas pela instituição, maior se torna a dificuldade de que a pena atinja a finalidade prevista, seja em razão das instalações inadequadas ou da ausência de cursos profissionalizantes e trabalho a ser oferecido aos detentos.

A Carta Cidadã trouxe direitos e garantias fundamentais, consagrando a "dignidade da pessoa humana", no art. $1^{\circ}$, III, qualidade intrínseca e distintiva de cada ser humano que o faz merecedor do mesmo respeito e consideração por parte do Estado e da comunidade. Além disso, como mecanismo de garantia temos a prevalência dos direitos humanos, nos termos do art. $4^{\circ}$ da Constituição Federal de 1988, que são conceituados como "direitos que o homem possui por sua própria natureza humana e pela dignidade a ele inerente".

Nas palavras de Fernando Barcellos de Almeida (1996, p.24), "são as ressalvas e restrições ao poder político ou as imposições a este (...) destinados a fazer respeitar e concretizar as condições de vida que possibilitem a todo ser humano manter e desenvolver suas qualidades peculiares de inteligência, dignidade e consciência". Mostra-se então evidente violação aos direitos humanos dos encarcerados, bem como a falência do sistema penitenciário da forma como se encontra, pelos números de detentos e pelo "déficit" de vagas.

\section{A RECUPERAÇÃO DO SISTEMA ATRAVÉS DA PRIVATIZAÇÃO}


Impulsionado na década de 80 nos Estados Unidos (EUA), devido a superlotação do sistema penitenciário, o processo de privatização dos presídios não é novidade da modernidade, segundo Mattos (2009, p. 51),

[...] essa proposta de privatização, agora também nos presídios, vendida como moderna, mas, na verdade, velha de 1819 pelo menos, fez me lembrar da fala do príncipe Fabrizio Salina, no magistral romance de Tomasi de Lampedusa, Il Gattopardo: ' Tudo será diferente, mas será pior'. Pode-se garantir o pior desde já. A privatização transforma ainda mais o preso em mercadoria e, por via de consequência, a pergunta que não cala é a seguinte: quem pagará esse pacto? $\mathrm{O}$ lucro do 'investidor' na contenção é pago pelo preso e sua família ou pelo preso, sua família e todos nós? Por que mais do mesmo? Mais do pior? Por que mais do pior? Como se fosse um jogo, porque apostar no perdedor? Que logica, é essa?

A crise no sistema de penitenciário vem estimulando a necessidade de uma reinvenção, diversos países vêm adotando a privatização em seu sistema penitenciário, tendo em vista a péssima gestão pública dos presídios e o alto nível de corrupção em relação às verbas. Aliás o sistema penitenciário não é pauta de preocupação política, ocasionando o descaso e abandono do mesmo.

Em nosso país, o primeiro estudo que se tem conhecimento no que condiz ao tema foi elaborado por Edmundo Oliveira, em 27 de Janeiro de 1992, e apresentado ao Conselho Nacional de Política Criminal e penitenciária, denominado de "Proposta de Regras Básicas para o Programa de Privatização do Sistema Penitenciário do Brasil” (OLIVEIRA, 2002, p. 336).

O autor apresentou a privatização como solução dos problemas do sistema penitenciário, como a superlotação e o baixo índice de ressocialização, além de diminuição dos gastos por parte do Estado, diante da perspectiva que a iniciativa privada conseguiria oferecer um serviço melhor, por um valor menor.

Na explicação de Grecianny Cordeiro (2014, p. 94):

Baseado num cuidadoso estudo feito acerca do tema, Edmundo Oliveira defendeu a privatização das prisões brasileiras acreditando que, dessa forma, poderia ser resolvido o problema de superpopulação carcerária, além de propiciar uma verdadeira ressocialização dos presos. Acreditava, ainda, que finalmente as regras insculpidas na Lei de Execução Penal seriam observadas, tudo isso, a um custo reduzido.

Oliveira (2002), trazia nessa proposta, a possibilidade de adotar um sistema misto, onde haveria participação do Estado e da iniciativa privada, sendo o Estado responsável pela direção do 
estabelecimento, e a iniciativa privada responsável por fornecer os serviços de hotelaria. Ou seja, não seria entregue a iniciativa privada todos os poderes sobre a execução da pena como é no modelo norte-americano. Laurindo Dias Minhoto (2000, p. 168) explica que a proposta feita por Edmundo tinhas as seguintes finalidades:

a. Atender aos preceitos constitucionais da individualização da pena e de respeito à integridade física e moral do preso;

b. lançar uma política ambiciosa de reinserção social e moral do detento, destinada a confiar nos efeitos da reabilitação e a refrear a reincidência;

c. introduzir, no sistema penitenciário, um modelo administrativo de gestão moderna;

d. reduzir os encargos e gastos públicos;

e. favorecer o desenvolvimento de salutar política de prevenção da criminalidade, mediante a participação organizada da comunidade nas tarefas de execução da pena privativa de liberdade;

f. aliviar, enfim, a dramática situação de superpovoamento, no conjunto do parque penitenciário nacional.

Porém, mesmo com alguns Estados demonstrando interesse na adoção da proposta, a Ordem dos Advogados do Brasil, o Ministério Público e a Magistratura foram contrários ao projeto, sob a alegação de que além de ser inconstitucional, seria um retrocesso.

Em 1999 o tema foi retomado e apresentado o projeto de Lei 2.146/99, por parte do deputado Federal Luís Barbosa, visando consentir ao Poder Executivo a privatização dos presídios, de modo que os Estados se tornariam "autorizados a firmar contratos de concessão com entidades particulares, visando à construção e exploração de Casas de Correção" (CORDEIRO, 2014, p. 95).

Entretanto, da mesma maneira que o anterior, submetido à apreciação do Conselho Nacional de Política Criminal e Penitenciaria, o projeto foi rejeitado, sob a alegação de falta de amparo constitucional.

Ainda diante da rejeição do projeto de lei do parlamentar, alguns estados da Federação firmaram contratos de concessão com empresas particulares, seja para construção ou exploração de estabelecimentos penitenciários (CORDEIRO, 2014. p. 96). Dessa forma, surgiu a primeira experiência de privatização de presídios no país, a Penitenciária Industrial de Guarapuava, no Paraná, inaugurada em 12 de novembro de 1999, seguida pela Penitenciária Industrial do Cariri, no Ceará.

\subsection{Modalidades de privatização}


Inicialmente é necessário distinguir os três sistemas que podem ser adotados pelos Estados na atualidade e que definem a forma de execução da pena: sistema estatal, o privado e o comunitário.

No sistema Estatal, a execução da pena é de total responsabilidade do Estado, não existindo nenhum tipo de participação privada, ao contrário do sistema privado, no qual a execução tem a participação privada, podendo ser realizada em maior ou menor grau de atuação.

Por último, o sistema comunitário, como o próprio nome aponta, a execução da pena é de responsabilidade da comunidade, que gerencia os recursos públicos disponibilizados pelo Estado, e a realiza sem fins lucrativos e organizações não governamentais. Trataremos, neste trabalho, sobre recuperação do sistema penitenciário através da privatização, que consiste na aplicação da segunda modalidade.

Entretanto, conforme mencionado, a participação privada pode ser efetivada em maior ou menor grau, situação que gera modalidades diversas de privatização. Apesar da divergência doutrinária quanto ao número de modalidades de privatização existentes, para esse trabalho será considerado o entendimento de Grecianny Carvalho Cordeiro (2014) corroborado por Pedro Armando Egydio de Carvalho (1994), que aponta que a privatização pode se dar em sentido amplo ou em sentido estrito.

No primeiro caso, a iniciativa privada abrange a parte material e pessoal, cabendo ao particular executar, por completo, a pena imposta pelo Judiciário e, no segundo, é realizada através do fornecimento dos serviços pertinentes à administração material do estabelecimento prisional. (CORDEIRO, 2014, p. 73), distinção que iremos abordar.

\subsubsection{Privatização em sentido amplo}

Trata-se do gerenciamento privado de estabelecimentos prisionais, de modo que o Estado deve transferir ao particular a responsabilidade de execução da pena do condenado. A iniciativa privada será responsável desde a construção da unidade, a administração e controle, não havendo participação ou atuação do Estado (CORDEIRO, 2014, p. 74). Entretanto, ainda compete ao Estado a fiscalização da preservação de direitos inerentes ao indivíduo, devendo ser zelada a dignidade dos detentos.

A respeito da forma de firmamento desse modelo, Laurindo Dias Minhoto (2000, p. 70) afirma que pode ser feito com o objetivo do particular assumir a administração de 
estabelecimentos já existentes, ou então, com o objetivo de construção e posterior administração de novos estabelecimentos.

Trata-se de uma modalidade menos utilizada, visto que a mais controvertida, diante da ausência de atuação Estatal, sendo questionável ainda se nesta modalidade haveria, de fato, a redução de custos para o poder Público (MINHOTO, 2000, p. 70), além de ser criticada a discricionariedade das decisões por parte da empresa dentro das prisões (Ibidem, p. 88). O modelo de gerenciamento privado é o adotado em alguns estabelecimentos nos Estados Unidos da América, que iniciou a privatização do seu sistema penitenciário na década de 80.

\subsubsection{Privatização em sentido estrito}

Consiste no gerenciamento privado dos serviços penitenciários, ou seja, recai sobre os serviços contratados, conforme explana Grecianny Carvalho Cordeiro (2014, p.75):

Os serviços contratados com a iniciativa privada geralmente dizem respeito aos serviços de hotelaria (alimentação, vestuário, lazer etc), cabendo também à empresa contratada fornecer aos presos serviços médico-odontológicos, assistentes sócias, psicológicos, psiquiatras e advogados, além de ofertar trabalho e educação.

Percebe-se que existe uma parceria entre o ente público e o privado, nessa toada, elucidam Luiz Ermes Bordin e Paulo Helder Bordin (2013, p. 42/43) que a responsabilidade pela administração penal, administração da unidade e execução da pena permanece sendo monopólio estatal. Consiste então em terceirização de serviços, sendo denominada também de cogestão, regime de dupla responsabilidade, compartilhado ou, ainda, sistema misto.

Esse sistema é utilizado na França, e no Brasil em determinadas localidades. Os estabelecimentos que costumam adotá-lo, geralmente são "penitenciarias industriais", onde empresas privadas são ali instaladas para a utilização da mão-de-obra carcerária, conforme aponta Cordeiro (2014, p.75).

Ainda de acordo com Cordeiro (2014), existe ainda a possibilidade de a empresa privada construir o estabelecimento penitenciário e arrendá-lo para o Estado, que será responsável por toda a execução da pena. 
A participação da empresa particular se limita ao projeto, financiamento e construção do presídio não produzindo qualquer atividade afeta a execução da pena. Tratando se arrendamento ou leasing, depois de determinado período de tempo, em geral longo, o imóvel passa a ser de propriedade do Estado (CORDEIRO, 2014, p.75).

Esse modelo também tem sido utilizado nos Estados Unidos, por alguns estados, sob o argumento de ser menos oneroso aos cofres públicos. Trata-se de formas diversas de privatização, sendo que esta última já é encontrada em estados brasileiros, conforme iremos analisar.

\subsection{Experiências de privatização no Brasil: terceirização e parceria público-privada}

Conforme mencionado, apesar de não existir permissão legal para a privatização de presídios no Brasil, alguns estados têm inserido a iniciativa privada através de terceirização de serviços, ou de parcerias público-privadas, utilizando-se da Lei n. 11.079/2004

Sobre essas relações estabelecidas entre o Ente Público e o privado para os fins de aplicação da pena, Luiz Ermes Bordin e Paulo Hélder Bordin (2003, p.42/43) ressaltam que

Há muito a Administração Pública vem utilizando parcerias com a iniciativa privada para a execução de suas atribuições. Sempre se disse que podem ser terceirizadas as atividades-meio, de que não decorram atos administrativos e onde não há delegação de parcela do poder estatal. É o caso da operacionalização das penitenciárias pela iniciativa privada, um sistema de cogestão ou gestão compartilhada. Mas, neste caso, a ação da empresa privada se restringe à execução de serviços operacionais, onde há diferença entre a atuação do servidor público e de um empregado da empresa. A diferença (vantagem) está na eficiência da iniciativa privada.

A experiência pioneira do país que utilizou o sistema de terceirização foi a Penitenciaria Industrial de Guarapuava no Paraná. A empresa responsável pelo presídio era a "Humanitas Administração Prisional Privada/SC Ltda", que prestava os serviços de "hospedagem, recursos humanos, manutenção, segurança, alimentação, saúde, recreação, serviço psicológico, educacional, jurídico" (CORDEIRO, 2014, p.104) e ao Estado cabia controle e supervisão da penitenciaria.

De acordo com informações disponibilizadas pelo DEPEN do Paraná, os presos que trabalham são divididos em três turnos, e recebem $75 \%$ do salário mínimo, sendo os outros $25 \%$

\footnotetext{
\# A Lei n. 11.079 de 30 de dezembro de 2004, institui normas gerais para licitação e contratação de parceria públicoprivada no âmbito da administração pública.
}

Rev. de Direito Penal, Processo Penal e Constituição | e-ISSN: 2526-0200 | Evento Virtual | v. 6 | n. 1 | 
são repassados ao Fundo Penitenciário do Paraná e são revertidos em recursos para melhorar as condições de vida dos presos. A empresa recebia por detento uma média de R \$ 1.200,00 (um mil e duzentos reais), e "o índice de reincidência era apontado como sendo de $6 \%$, enquanto no restante do país chegava a 70\%" (CORDEIRO, 2014, p.104).

A penitenciaria de Guarapuava passou a ser um modelo prisional, que acabou sendo adotado por outros estabelecimentos, no estado do Paraná e em outros estados. Contudo, no ano de 2006 quando os contratos com a empresa venceram, Roberto Requião, o então governador do Estado do Paraná optou por não os renovar, retomando a gestão por parte da administração pública.

Outra experiência adotada no Brasil foi a privatização através de parceria públicoprivada; inaugurado em Janeiro de 2013 o Complexo Prisional de Ribeirão das Neves, na região Metropolitana de Belo Horizonte - MG, é administrado pelo "Consorcio Gestores Prisionais Associados (GPA), grupo formado por cinco empresas” (CORDEIRO, 2014, p.110).

Tal parceria pode consistir em um contrato administrativo de concessão, com finalidade de execução de serviço público, mediante tarifa paga pelo próprio usuário e contraprestação pecuniária do parceiro público, ou ainda na prestação do serviço de que a Administração Pública seja a usuária direta ou indireta, mediante contraprestação.

O estado estabeleceu um contrato de 27 (vinte e sete) anos com a iniciativa privava por meio de licitação, para que a empresa construísse o estabelecimento e posteriormente fizesse sua administração.

Nesse caso, permanece como poder do Estado as Questões disciplinares e de segurança (Poder de Polícia), controle de execução da pena, transporte de presos (escoltas) e a fiscalização. Por outro lado, cabe a empresa a gestão do complexo penitenciário, assim como os planos operacionais e de ressocialização, prestação de contas, entrega do empreendimento, ao fim do contrato, em excelentes condições etc.

O complexo prisional de Ribeirão das Neves é o primeiro a funcionar nessa modalidade no país. Conclui-se assim, ao analisar a primeira experiência de presídio terceirizado e o primeiro no sistema de parceria público-privada, é possível verificar que ambos surgiram com o objetivo de melhoraria dos problemas enfrentados pelo sistema penitenciário, valendo-se de uma lei não especifica e da conivência das autoridades competentes.

A prisão, sobretudo nos moldes atuais, não é o ambiente correto para se ressocialização, pelo contrário, é um ambiente de completa segregação social, por isso, jamais atingirá seu 
proposito funcional de recuperação. Diante desta impotência estatal é que surgem alguns novos métodos e parcerias para gestão de presídios, que gerenciam desde a totalidade, como a parcialidade da instituição. Aqui, insta ressaltar, que a abordagem realizada acerca da privatização de presídios no Brasil, foi meramente exemplificativa, pois abordou-se apenas dois estabelecimentos.

\subsection{Prós e Contras a privatização}

Enquanto para os defensores, dizer não à privatização é concordar com o caos instalado em prisões que são verdadeiras universidades do crime (OLIVEIRA, 2002, p. 332), para os críticos, a privatização não pode ser efetivada diante da inconstitucionalidade, pois o Estado, não estaria legitimado para transferir o poder de coação que é exclusivamente seu, cabendo somente ao Estado a privação da liberdade.

No que condiz aos custos, Laurindo Dias Minhoto (2002, p.135) defende que os mesmos são aceitos diante dos resultados benéficos:

$\mathrm{O}$ verdadeiro critério a ser analisado é a adaptação do infrator à sociedade. As diferenças entre os custos do setor público e privado tornam-se realmente aceitos no momento em que surgem os efeitos esperados do sistema prisional.

Por outro lado, o interesse da empresa estaria associado a obtenção de lucro - e não de atingir as finalidades da pena, o que viria através do valor pago pelo Estado por preso, além da exploração do trabalho do detento dentro dos estabelecimentos.

De acordo com Guilherme de Souza Nucci (2009, p. 455), o trabalho do preso, ao gerar lucro para empresas privadas, consiste em uma distorção do processo de execução da pena. O preso receberia três quartos do salário mínimo e produziria bens e produtos de alto valor, aos quais a iniciativa privada ficaria com o lucro, sem conceder ao condenado os benefícios da Consolidação das Leis do Trabalho, situação seria ilegal diante do cumprimento da pena ser um ônus estatal a ser suportado.

Por fim, enquanto os críticos argumentam sobre a possibilidade de encarceramento em massa, e falta de preocupação com a ressocialização, diante do interesse da empresa gestora no maior número de detentos, os defensores apontam para a redução da superlotação carcerária, como na mencionada parceria público-privada em Belo Horizonte, no qual é vedado que haja "déficit" 
de vagas tendo, por consequência, melhoria das condições mínimas gerando maior possibilidade de atingir as finalidades da pena, relativas a prevenção, reinserção e retribuição.

As penitenciarias encontram-se superlotadas, não havendo mais espaço para tantos detentos. As organizações criminosas tomaram o lugar do Estado no gerenciamento interno dos presídios, recrutando cada novo indivíduo que adentra o sistema. A pessoa que adentra o presidio atualmente não tem escolha de cumprir sua pena e se reformar, ele é "obrigado" a integrar o estado paralelo que sobrevive e se alimenta, dentro do próprio sistema carcerário.

Segundo Baratta (2013, p. 193) "o cárcere não tem mais aquela função real de reeducação e de disciplina, que possuía em sua origem”, o cárcere é, antes de tudo, estigmatizante e deve ser o último recurso na persecução penal.

A valorização humana, o investimento no encarcerado é talvez a maior esperança ao combate da criminalidade, presenciamos uma corrente de forças, onde de um lado temos o Estado que extrapola seu papel punitivista e de outro o preso, marginalizado e sem perspectivas de ressocialização, e a sociedade indiferente, num patamar neutro, como vítima ideal do sistema.

\section{CONCLUSÃO}

Diante dos dados apresentados, a falência do sistema penitenciário brasileiro se torna ainda mais visível, não sendo possível que a pena atinja a finalidade prevista no ordenamento jurídico.

Em que pese as críticas apontadas sobre a privatização do sistema, não há perspectiva de melhoria no status quo e ainda que não exista regulamentação especifica atualmente quanto a privatização, os estados se valem da lei n. 11.079 de 30 de dezembro de 2004, que institui normas gerais para licitação e contratação de parceria público-privada no âmbito da administração pública.

Importante ressaltar que os modelos de privatização mais difundidos, e tidos como exemplos são o Norte-Americano e o Francês, que incorporaram seus respectivos modelos quando seus sistemas penitenciários estavam em crise como o brasileiro atualmente.

Ocorre que a presença de empresas privadas dentro dos presídios acontece há quase duas décadas no Brasil, e não há nada que regularize ou de parâmetros básicos específicos sobre o tema para serem seguidos pelas empresas e pelos estados, situação que geraria melhor fiscalização estatal. 
Trata-se então de discussão tardia, cabendo uma análise da atuação da parceria públicoprivada e dos benefícios ou malefícios da mesma, em comparação com o monopólio estatal de aplicação e execução da pena, diante da efetivação das finalidades previstas para esta.

Aliás, vale observar ainda que a resistência decorrente do misoneismo jurídico, tem como consequência a manutenção de um sistema em afronta aos preceitos constitucionais, situação que deve ser refletida, uma vez que mesmo diante da privatização, caberá ao Estado a fiscalização dos estabelecimentos penais, através do juízo da execução penal, pelo Ministério Público, pelo Conselho Penitenciário e pelo Departamento Penitenciário local.

Em resumo, trata-se de uma busca de melhoraria do sistema penitenciário, não necessariamente pela privatização ampla e completa, mas de uma parceria entre o Estado e o particular, devendo - inclusive, o Estado reincidir o contrato quando não satisfatório.

Trata-se de uma alternativa para diminuir os gastos do Estado e melhorar o sistema, para que assim, a pena cumpra a sua de função social de ressocialização e não apenas de instrumento de segregação e marginalização.

\section{REFERÊNCIAS}

ALMEIDA, Fernando Barcellos de. Teoria Geral dos Direitos Humanos. Porto Alegre: Editor Sérgio Antônio Fabris, 1996.

BARATTA, Alessandro. Criminologia crítica e crítica do direito penal: introdução à sociologia do direito penal. Tradução de Juarez Cirino dos Santos. 6. ed. Rio de janeiro: Editora Revan, 2013. Instituto Carioca de Criminologia.

BECCARIA, Cesare; BONESANA, Marchesi Di. Dos delitos e das penas. Tradução de Deocleciano Torrieri Guimarães. São Paulo: Riddeel, 2003. Título original: Dei delitti e delle pene (1764).

BITTENCOURT, Cézar Roberto. Falência da pena de prisão: causas e alternativas. 4. ed. São Paulo: Saraiva, 2011.

BOBBIO, Norberto. A era dos direitos. Tradução de Carlos Nelson Coutinho. Rio de Janeiro: Campus, 1992.

BORDIN, Paulo Hélder e BORDIN, Luiz Ermes. Operacionalização de Penitenciárias: a iniciativa privada como parceira do Estado. Revista Jurídica Consulex, Brasília, ano VII, n. 161, p. 42-3, 30 set. 2003. 


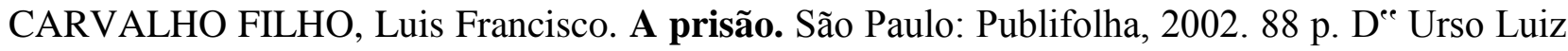
Flávio Borges, A Privatização Dos Presídios, revista superinteressante, abril 2002, disponibilizada em . Acesso em: 03 de maio de 2019.

CARVALHO, Pedro Armando Egydio de. É conveniente privatizar os presídios? Revista Brasileira de Ciências Criminais, Revista dos Tribunais, ano 2, n. 7, p. 133-116, jul.-set. 1994.

CARVAlHO, Salo de. Pena e Garantias. Rio de Janeiro: Lúmen Júris, 2003.

CONSELHO NACIONAL DE JUSTIÇA (CNJ). Dados Das Inspeções Nos Estabelecimentos Penais. Disponível em: <https://www.cnj.jus.br/inspecao_penal/mapa.php>. Acesso em 14 de abril de 2020 .

CORDEIRO, Grecianny Carvalho. Privatização do Sistema Prisional Brasileiro. 2. ed. Rio de Janeiro: Livraria Freitas Bastos, 2014.

FERRÉ OLIVÉ, Juan Carlos; Roxin, Claus. Direito penal brasileiro: parte geral: princípios fundamentais e sistema. São Paulo: RT, 2011.

GARCIA - PABLOS Y MOLINA, Antonio. Regimen aberto y ejecusión penal. REP, n. 240, 1988.

GARÓFALO, Rafael. Estudios Criminalistas. Madrid, Tipografica de Alfredo Alonso 1896.

GIACÓIA, Gilberto, HAMMERSCHMIDT, Denise; FUENTES, Paola Oviedo. A prisão e a condição humana do recluso. Revista Argumenta. Jacarezinho, n. 15, p. 131-161, 2011. Disponível em: <http://seer.uenp.edu.br/index.php/argumenta/article/view/202/201>. Acesso em: 28 out.

INSTITUTO DE PESQUISA ECONÔMICA APLICADA (IPEA). Reincidência Criminal no Brasil: relatório de Pesquisa. Rio de Janeiro, 2015. Disponível em: < https://www.ipea.gov.br/agencia/images/stories/PDFs/relatoriopesquisa/150611_relatorio_reincide ncia_criminal.pdf >. Acesso em 03 de abril de 2020.

JESUS, Damásio de. Manual de Direito Penal. V. I. São Paulo: Atlas, 2004.

KLOCH, Henrique. O sistema prisional e os direitos da personalidade do apenado com fins de ressocialização. Henrique Kloch, Ivan Dias da Motta. Porto Alegre: Verbo Jurídico, 2008.

MACAULAY, Fionaet al. Segurança pública e violência: o estado está cumprindo o seu papel?. 1. ed. São Paulo: contexto, 2006.

MATTOS, Virgílio. O que já era ruim pode ficar ainda pior - Estudos de execução criminal direito e psicologia. Belo Horizonte: Tribunal de Justiça de Minas Gerais, 2009.

MINHOTO, Laurindo Dias. Privatização de Presídios e Criminalidade: A Gestão da Violência no Capitalismo Global. São Paulo: Max Limonad, 2000. 
MINISTÉRIO DA JUSTIÇA E SEGURANÇA PÚBLICA. Departamento Penitenciário Nacional. Levantamento Nacional de Informações Penitenciárias (Infopen) - período referente a dezembro de 2019. Disponível em: http://depen.gov.br/DEPEN/depen/sisdepen/infopen.

NUCCI, Guilherme de Souza. Leis Penais e Processuais Penais Comentadas. 4. ed. São Paulo: Editora Revista dos Tribunais, 2009.

OLIVEIRA, Edmundo. O Futuro Alternativo das Prisões. Rio de Janeiro: Forense, 2002.

SANTIAGO, Mir Puig. Direito penal: fundamentos e teoria do delito. Trad. Claudia Viana Garcia, José Carlos Nobre Porciúncula Neto. São Paulo: RT, 2007.

SILVA, Haroldo Caetano da. Manual de Execução Penal. 2. ed. Ed. Campinas: Bookseller, 2002. 